\title{
Epidemiology of colorectal cancer: incidence, mortality, survival, and risk factors
}

\author{
Prashanth Rawla ${ }^{1}$, Tagore Sunkara ${ }^{2}$, Adam Barsouk ${ }^{3}$ \\ ${ }^{1}$ Hospitalist, Department of Internal Medicine, SOVAH Health, Martinsville, VA, USA \\ ${ }^{2}$ Gastroenterology and Hepatology Attending Physician, Mercy Medical Centre, Des Moines, IA, USA \\ ${ }^{3}$ Hillman Cancer Center, University of Pittsburgh, PA, USA
}

Gastroenterology Rev 2019; 14 (2): 89-103

DOI: https://doi.org/10.5114/pg.2018.81072

Key words: colorectal cancer, epidemiology, incidence, risk factors.

Address for correspondence: Prashanth Rawla, Department of Internal Medicine/Hospitalist, SOVAH Health, Martinsville, VA, 24112 USA, phone: 732-982-7357, e-mail: rawlap@gmail.com

\begin{abstract}
According to GLOBOCAN 2018 data, colorectal cancer (CRC) is the third most deadly and fourth most commonly diagnosed cancer in the world. Nearly 2 million new cases and about 1 million deaths are expected in 2018. CRC incidence has been steadily rising worldwide, especially in developing countries that are adopting the "western" way of life. Obesity, sedentary lifestyle, red meat consumption, alcohol, and tobacco are considered the driving factors behind the growth of CRC. However, recent advances in early detection screenings and treatment options have reduced CRC mortality in developed nations, even in the face of growing incidence. Genetic testing and better family history documentation can enable those with a hereditary predisposition for the neoplasm to take preventive measures. Meanwhile, the general population can reduce their risk by lowering their red meat, alcohol, and tobacco consumption and raising their consumption of fibre, wholesome foods, and certain vitamins and minerals.
\end{abstract}

\section{Introduction}

Colorectal cancer (CRC) is already the third leading cause of cancer death in the world, and its incidence is steadily rising in developing nations. Also known as colorectal adenocarcinoma, CRC usually emerges from the glandular, epithelial cells of the large intestine. The cancer arises when certain cells of the epithelium acquire a series of genetic or epigenetic mutations that confer on them a selective advantage [1]. With abnormally heightened replication and survival, these hyper-proliferative cells give rise to a benign adenoma, which may then evolve into carcinoma and metastasize over decades [2].

The primary function of the colon is the reabsorption of water and remaining minerals and nutrients in the chyme. The large intestine contains diverse microflora that can break down remaining starches and proteins. In order to facilitate absorption, the gastrointestinal epithelium is organised as an axis of crypts and villi. Colon stem cells and progenitor cells are located in the bottom of the crypt. These pluripotent cells function in self-renewal [3]. As the progenitor cells differentiate into specialised epithelium cells, they migrate out of the crypt and up the villus. Differentiated epithelial cells include Paneth, goblet, and enteroendocrine cells as well as enterocytes. Once these cells arrive at the top of the villus after about 14 days, they undergo apoptosis, i.e. programmed cell death, and are shed and eliminated with the faeces [4]. This process is highly regulated by a gradient of signalling proteins, among which the most common are Wnt, BMP, and TGF-B [5].

The CRCS actually comprise a very heterogeneous group of diseases driven by a vast array of mutations and mutagens. Because not all CRCs share similar driving mutations, it has been difficult to design a "catchall" molecular therapy [6]. Surgery remains the primary course of treatment in cases of early diagnosis, but is no longer effective in advanced cases where cancer has metastasised, as is the case in about $25 \%$ of diagnoses [7]. In such patients, the efficacy of neoadjuvant, cytotoxic therapies has been stifled by the rapid evolution of drug resistance and cancer recurrence [8].

A stronger understanding of the pattern of CRC development, the environmental and genetic risk factors, and the molecular evolution of the disease can empow- 
er researchers and physicians to prevent and treat this deadly neoplasm.

\section{Epidemiology \\ Incidence}

According to GLOBOCAN 2018 data, cancer of the colon is the fourth most incident cancer in the world, while cancer of the rectum is the eighth most incident. Together, CRCs are the third most commonly diagnosed form of cancer globally, comprising $11 \%$ of all cancer diagnoses (Figure 1) [9, 10].

About 1,096,000 new cases of colon cancer are estimated to be diagnosed in 2018, while about 704,000 new cases of rectal cancer are expected. Together, these comprise 1.8 million new cases of CRC. CRC is the most diagnosed cancer among men in 10 of the 191 countries worldwide. No country has CRC as the most diagnosed cancer among women [9].

The CRC is more incident among men than women and 3-4 times more common in developed than in developing nations. Age-standardised (world) incidence rates per 100,000 of CRC in both sexes is 19.7, in males is 23.6, and in females is 16.3 (Figure 2) [11] While the age-standardised incidence rate among men is $30.1 / 100,000$ in high-HDI (human development index) nations, it is 8.4 in low-HDI nations (the same statistics for women are 20.9 and 5.9, respectively) [9].

In 2018, about 576,000 and 521,000 men and women, respectively, are projected to be diagnosed with colon cancer. This incidence constitutes a $1.51 \%$ cumulative risk of colon cancer among men age 0-74 years, and a $1.12 \%$ risk among women. About 430,000 men and 274,000 women are expected to be diagnosed with cancer of the rectum. Their cumulative, lifetime risks are $1.2 \%$ and $.65 \%$, respectively [9].

Developed countries are at the highest risk of colon and rectal cancer. For colon cancer, Southern Europe, Australia/New Zealand, and Northern Europe are the regions of highest incidence. For rectal cancer, these regions are Eastern Europe, Australia/New Zealand, and Eastern Asia. North America also features among the highest incidence rates for both cancers. The country with the highest incidence of CRC per 100,00 population is Hungary (70.6) among males and Norway (29.3) among females (Figure 3). In Japan, South Korea, Saudi Arabia, Oman, Yemen, UAE, Bahrain, Qatar, Kuwait, and Slovakia CRC is the most diagnosed cancer among men. Meanwhile, all regions of Africa, as well as Southern Asia, have the lowest incidence rates for both cancers between both sexes [9].

Overall, CRC incidence is highly variable by region, with up to eight-fold variations between countries. In countries undergoing a major developmental transition, incidence rates tend to rise uniformly with increasing HDI, suggesting a causal relationship [9].

Variation within a nation can also be steep. In the US, there was almost a three-fold higher incidence among those in Alaska relative to those in the Southwest. Factors that contribute to this variance are disparities in access to screenings and behaviour [12].

\section{Mortality}

The CRC is the second most deadly cancer worldwide, with about 881,000 deaths estimated for 2018 .

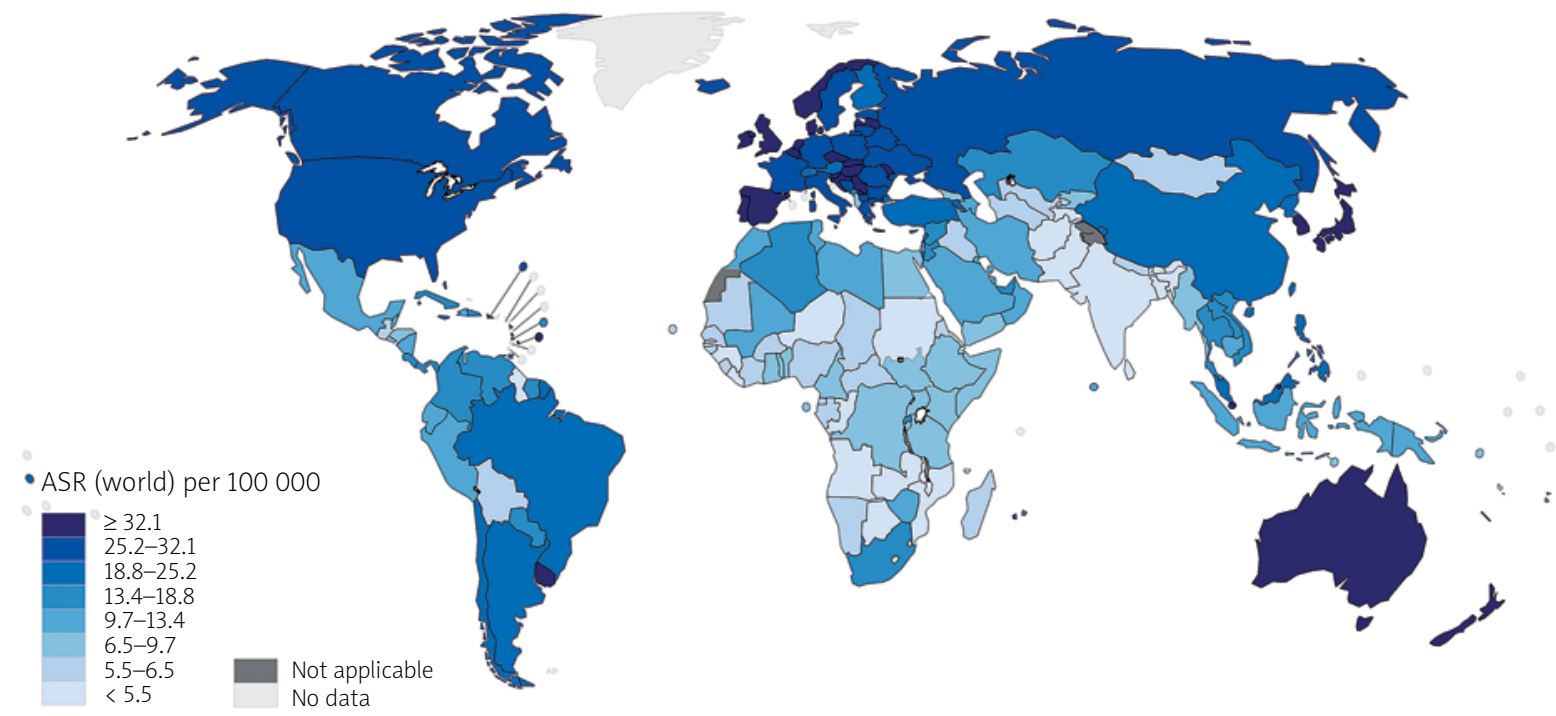

Figure 1. Map showing estimated age-standardised incidence rates (world) in 2018, colorectum, both sexes, all ages (reproduced from http://globocan.iarc.fr/ [10]) 

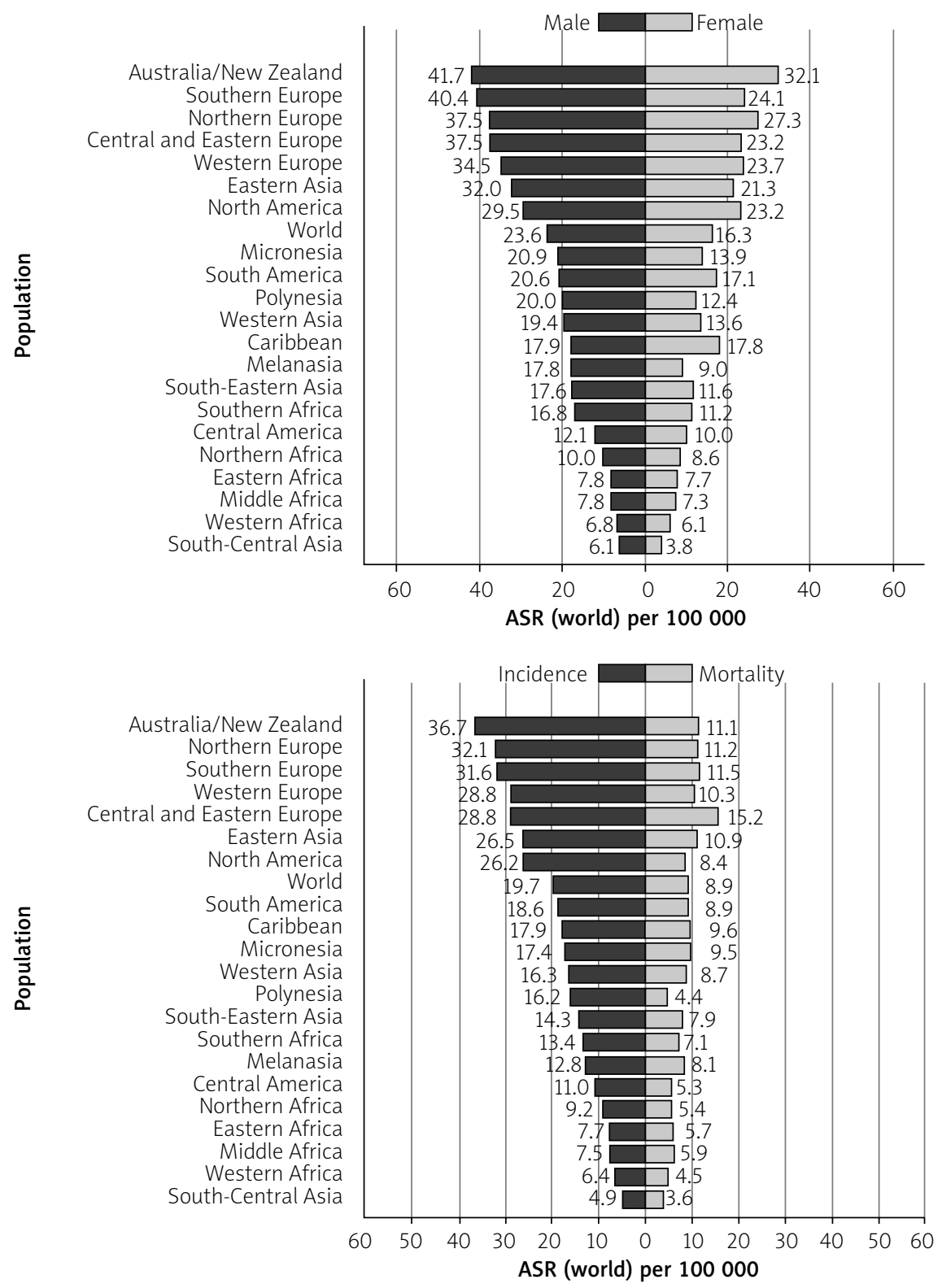

Figure 2. Bar chart showing age-standardised (world) incidence rates, colorectal cancer, by sex in 2018 on left side and age standardised (world) incidence and mortality rates, colorectal cancer in 2018 on right side (reproduced from http://globocan.iarc.fr/ [11])

Colon cancer is the fifth most deadly cancer with 551,000 deaths projected for 2018 , comprising $5.8 \%$ of all cancer deaths. Meanwhile, rectal cancer is the $10^{\text {th }}$ most deadly, with 310,000 deaths, which constitutes $3.2 \%$ of all cancer deaths. The cumulative risk, at age 0 to 74 years, of dying from colon cancer is $0.66 \%$ among men and $0.44 \%$ among women. The same risk for rectal cancer is $0.46 \%$ among men and $0.26 \%$ among women. Age-standardised (world) mortality rates per 100,000 of CRC in both sexes is 8.9 (Figure 4) [9].

The CRC is the deadliest cancer among males in three countries and the most deadly among females in five. In males, these countries are Saudi Arabia, Oman, and UAE (all of which also have CRC as the most incident cancer). In females, these countries are Algeria, Belarus, Japan, Spain, and Portugal [9]. The country with the highest mortality rates of CRC per 100,00 population is Hungary (31.2) among males and (14.8) among females (Figure 5).

The mortality from CRC varies with the developmental status of a nation, but to a lesser degree than incidence (about a 2-3-fold difference between low and high $\mathrm{HDI}$ ). The age-standardised mortality is 12.8/100,000 among males in high HDI nations and 
Estimated number of new cases in 2018, colorectal cancer, males and females, all ages

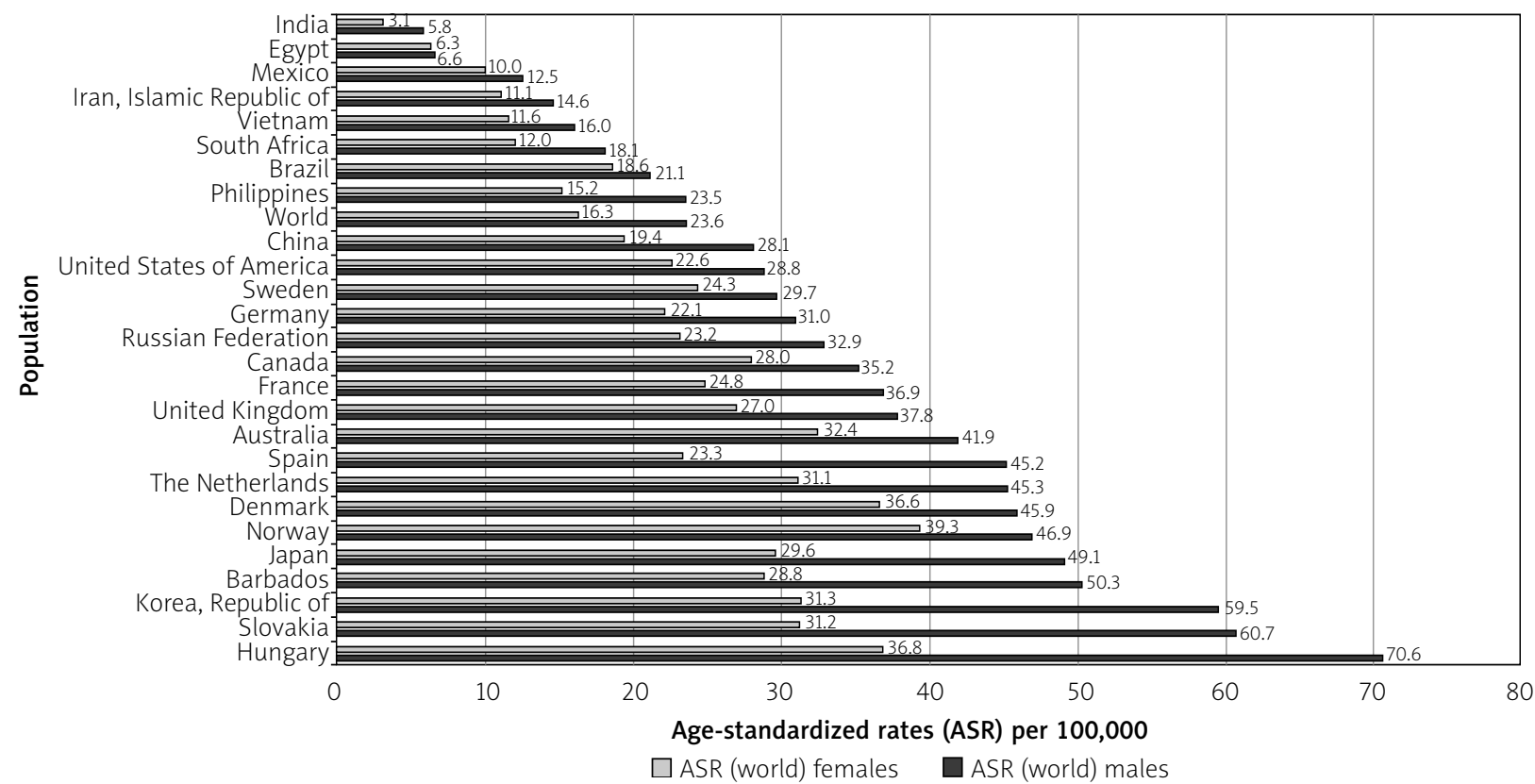

Figure 3. Bar chart showing country-specific age-standardised (world) incidence rates, colorectal cancer, by sex in 2018 (source http://globocan.iarc.fr/ [10])

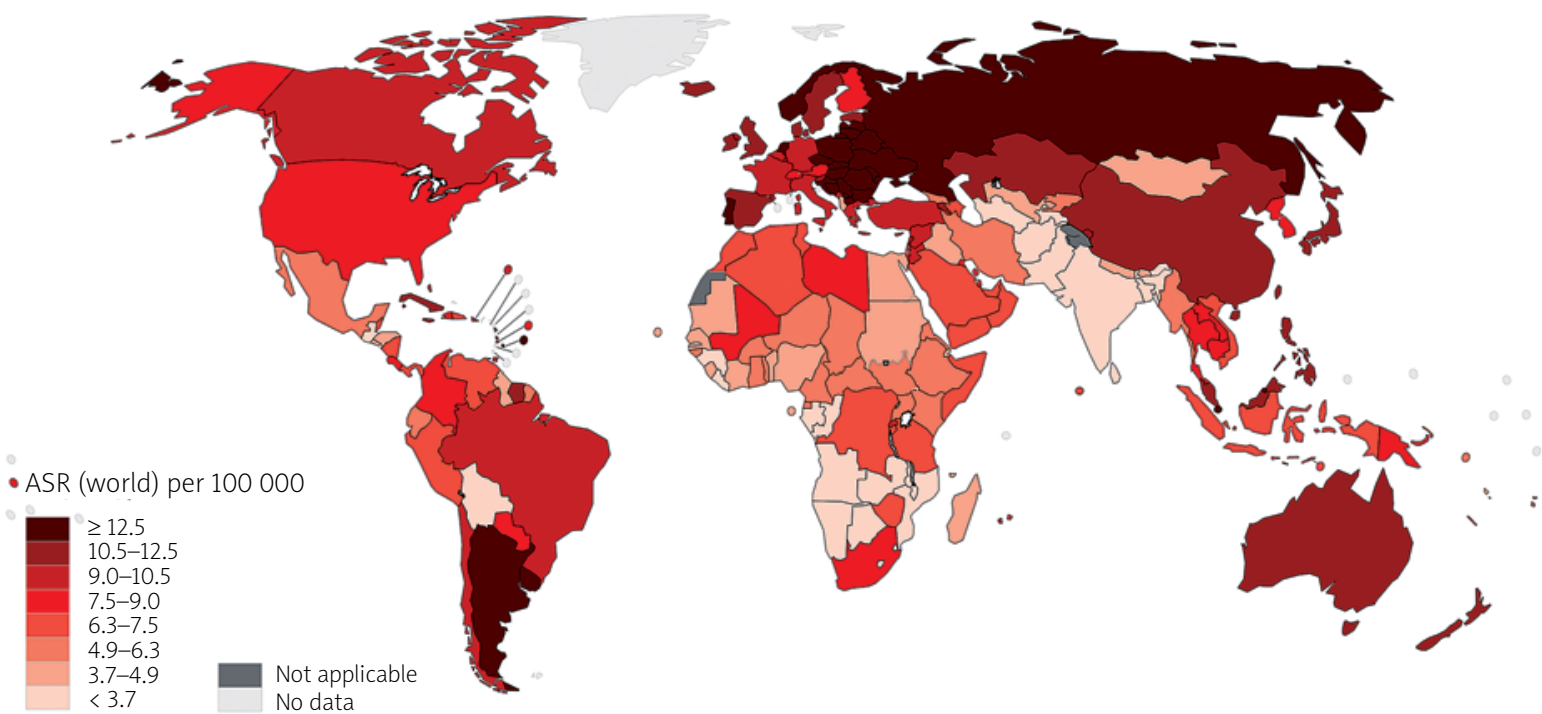

Figure 4. Map showing estimated age-standardised mortality rates (world) in 2018, colorectum, both sexes, all ages (reproduced from http://globocan.iarc.fr/ [10])

$5.7 / 100,000$ in low HDI nations. These same rates are 8.5 and 3.8 among females [9].

\section{Trends}

The relation between trends in CRC incidence and mortality can be characterised into three distinct global categories. The first category, which is comprised of medium HDI nations (often known as semi-periphery nations) such as Brazil, Russia, China, Latin America, the Philippines, and the Baltics, has witnessed an increase in both incidence and mortality in the past decade. These nations are undergoing an economic transition, which is probably the cause of the increase in CRC incidence. The second category, comprised of mostly high-HDI nations such as Canada, the United Kingdom (UK), Denmark, and Singapore, has seen an 
Estimated number of deaths in 2018, colorectal cancer, males and females, all ages

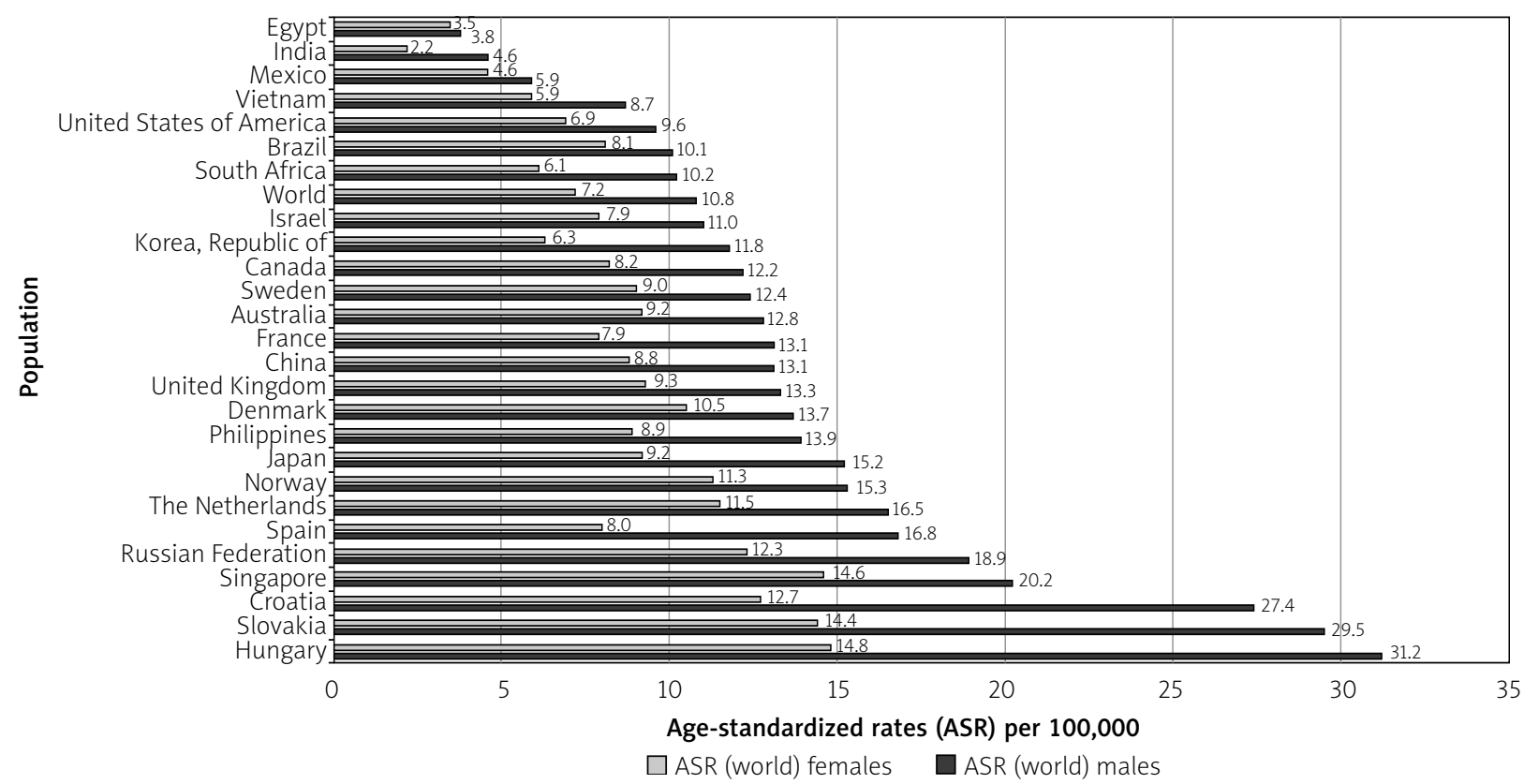

Figure 5. Bar chart showing country specific age-standardised (world) mortality rates, colorectal cancer, by sex in 2018 (source http://globocan.iarc.fr/ [10])

increase in incidence but drop-in mortality due to improved treatment options. Lastly, the third category of highest HDI nations such as the US, Iceland, Japan, and France has witnessed a drop in both mortality and incidence due to successes in prevention and treatment [13].

Nevertheless, while those over 50 years of age have seen decreases in CRC incidence in the US over the past decades, those aged 20-49 years have actually seen a growing incidence (Figure 6) [12]. The incidence rates of CRC for ages 20-49 years was 9.3 per 100,000 in 1975 and now is up to 13.7 per 100,000 in 2015, a percentage change of $47.31 \%$, whereas incidence rates in age groups 50 years and above has steadily decreased. Mortality rates have decreased overall, with the most significant decrease seen in the age group of $75+$ years (Figure 7).

The global burden of CRC is expected to increase by $60 \%$, to over 2.2 million new cases and 1.1 million annual deaths, by the year 2030. This growth is expected as a product of the economic development of transitioning and low-to-medium-HDI nations, as well as generational changes in developed nations. Increases in the incidence of CRC seem to increase uniformly with economic development. The growth is hypothesised to be a product of environmental changes, such as more sedentary lifestyle, greater obesity, processed food, alcohol, and meat consumption, and greater overall longevity [13].

\section{Survival}

Improvements in CRC treatment have led to decreases in CRC mortality in the second and third categories of nations, even in the face of increased incidence. A driver of greater survival has been the removal of polyps and other early detection efforts, such as colonoscopies, flexible sigmoidoscopies, computed tomography (CT) colonography, faecal immunochemistry, and faecal occult blood testing [14]. The introduction of better screening tests may have initially increased incidence rates due to the diagnosis of previously undiagnosed disease but has, in the long term, reduced mortality thanks to the removal of pre-cancerous or un-metastasised polyps [13].

The United States (US) is among the third category of highest HDI nations, which has seen a decrease in CRC incidence and mortality. The 5 -year relative survival rate for stage I colon cancer in the US is about $92 \%$. The rate for stage IIA and stage IIB is $87 \%$ and $65 \%$, respectively. Surprisingly, the 5 -year survival rate for stage IIIA and stage IIIB are slightly higher at $90 \%$ and $72 \%$, respectively. Stage IIIC has a survival rate of $53 \%$, while stage IV, or metastatic CRC, has a 5-year survival of only $12 \%$ [12].

The 5-year survival rates for rectal cancer are mostly slightly lower, with $88 \%$ for stage I, $81 \%$ for stage IIA, $50 \%$ for stage IIB, $83 \%$ for stage IIIA, $72 \%$ for stage IIIB, $58 \%$ for stage IIIC, and $13 \%$ for stage IV [12]. These stagings are based on the previous version of the TNM 


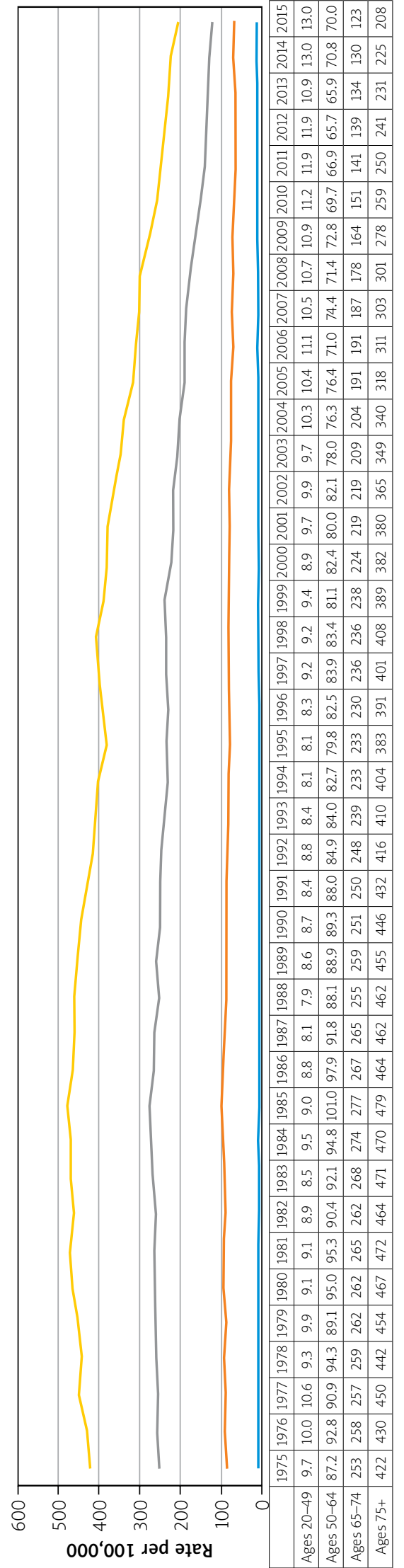

system. The equipment used for diagnosis and pace of various forms of CRC can explain the bizarre uptick in survival from stage II to stage III cancers [15].

Variations in survival within a nation can be race and status dependent. In the US, African Americans and Native Americans, underprivileged minorities often with less access to quality healthcare, pre-emptive screenings, and healthy foods, suffer lower survival among all stages of CRC (Figure 8) [16, 17].

\section{Etiology}

The CRC usually begins with the non-cancerous proliferation of mucosal epithelial cells. These growths are known as polyps and can grow gradually for 10-20 years before becoming cancerous. The most common form is an adenoma or polyp that originated from granular cells, whose function is to produce the mucus that lines the large intestine [18]. Only about $10 \%$ of all adenomas progress to invasive cancer, although the risk of cancer increases as the polyp grows larger. Invasive cancer arising from such polyps is known as adenocarcinoma and accounts for $96 \%$ of all CRCs [19].

The CRCs that grow into the wall of the colon or rectum can penetrate blood or lymphatic vessels, allowing metastasis to distant organs via the blood or to nearby lymph nodes. The extent of invasion determines the staging, and thus the prognosis, of a CRC diagnosis. In situ cancers are polyps that have not yet invaded the colon or rectum wall and are thus not reported as CRCs. Local cancers are cancers have grown into the wall but have not yet extended past it. Regional cancers are those that have invaded nearby lymph nodes or tissues, while distant cancers are those that have metastasised, via the bloodstream, to distant organs with capillary beds where they have taken root, such as in the lungs or liver.

Certain dietary and lifestyle choices can promote intestinal inflammation and modify the intestinal microflora to promote an immune response, both of which can facilitate polyp growth and conversion to cancer. Likewise, hereditary or spontaneous mutations in oncogenes and tumour-suppressor genes can provide certain mucosal cells with a selective advantage and encourage hyper-proliferation and ultimately carcinogenesis. Lifestyle modification, early colorectal screening, and genetic testing hold promise in preventing CRC.

\section{Non-modifiable risk factors}

\section{Race and ethnicity}

Variations in survival within a nation can be raceand ethnicity-dependent. In the US, African Americans and Native Americans have a higher incidence of CRC and suffer lower survival among all stages of CRC. 

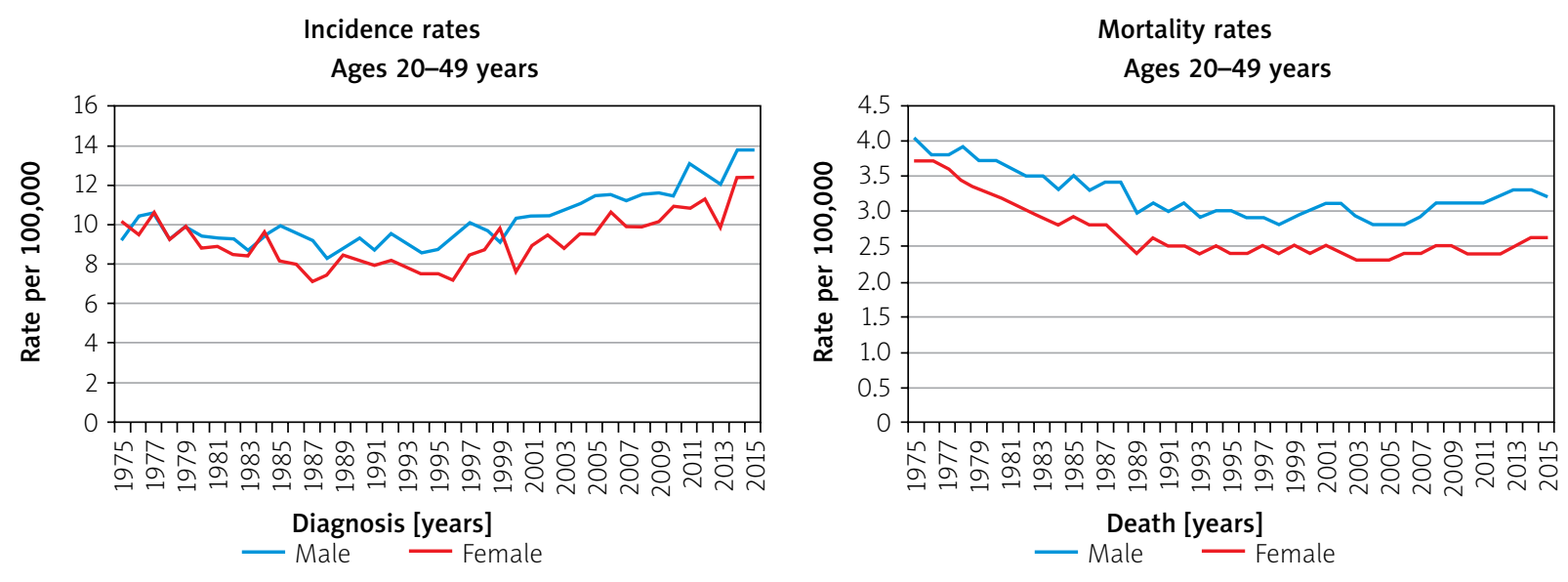

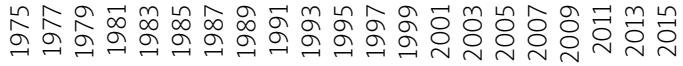

- Male - Femal

Ages 50-64 years

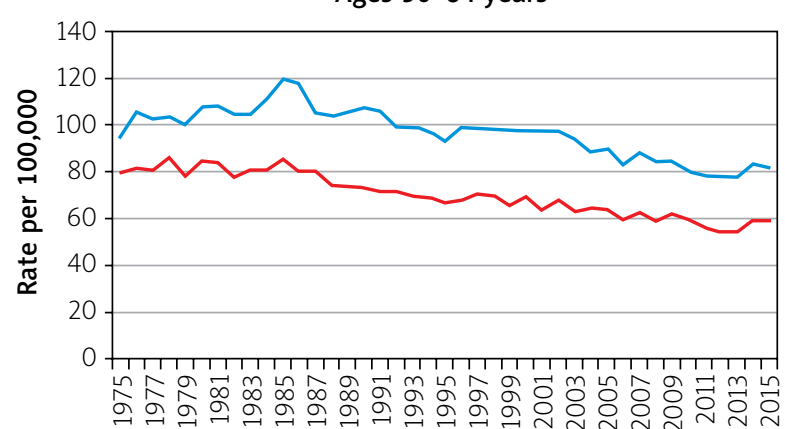

Diagnosis [years]

- Male - Female

Ages 65-74 years

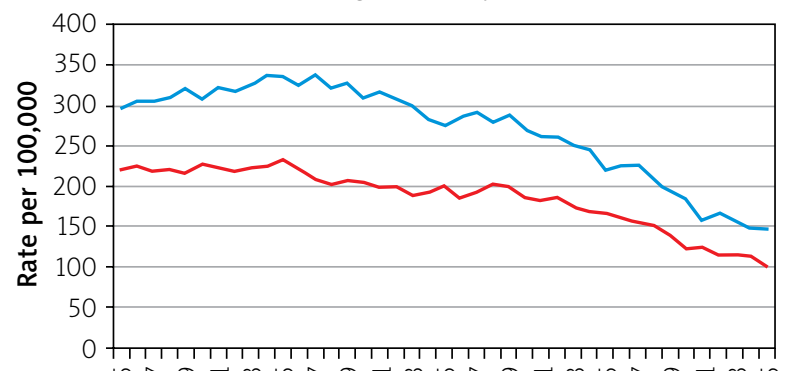

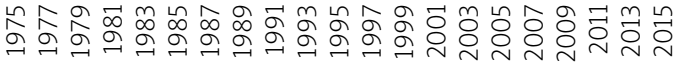

\section{Diagnosis [years] \\ - Male Female \\ Ages $75+$ years}

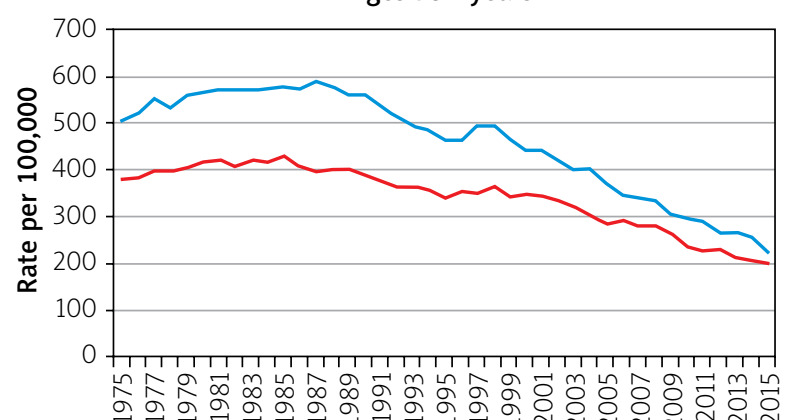

Diagnosis [years]

- Male - Female
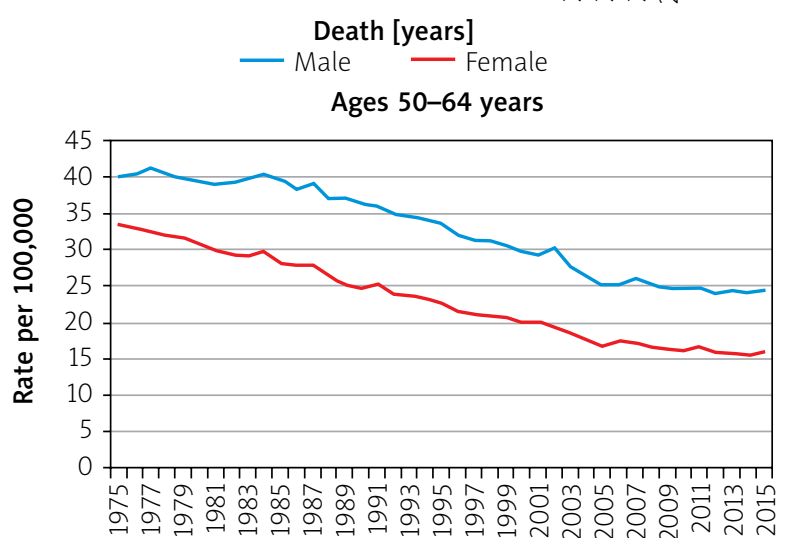

Death [years]

- Male - Female

Ages 65-74 years

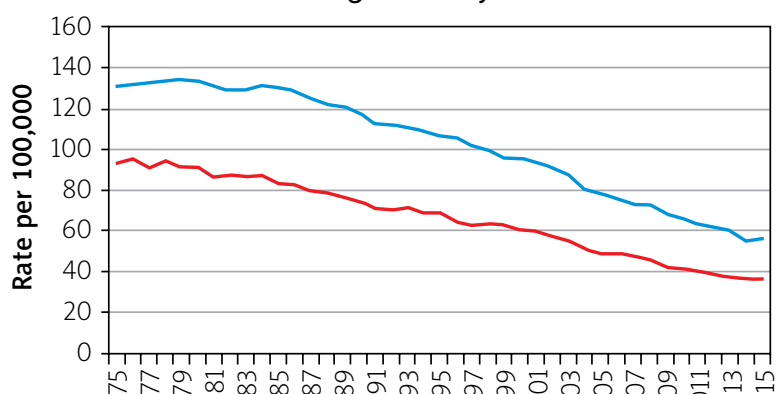

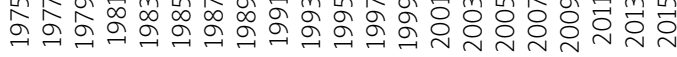

$$
\begin{gathered}
\text { Death [years] } \\
\text { Male } \quad \text { Female } \\
\text { Ages } 75+\text { years }
\end{gathered}
$$

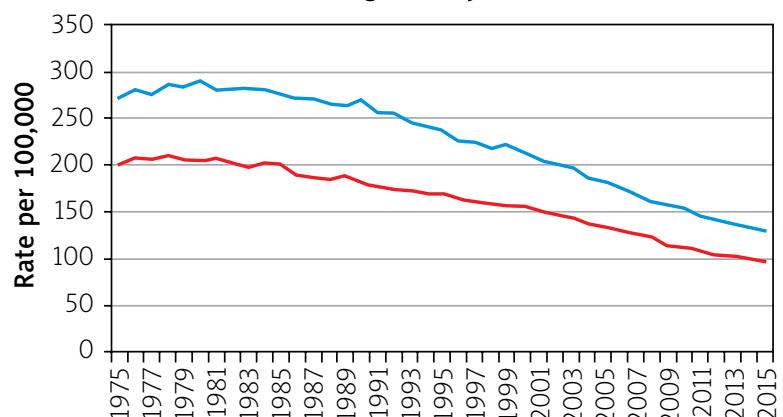
Death [years]

- Male - Female

Figure 7. Trends in colorectal cancer incidence (1975-2015) and mortality (1975-2015) rates by age and sex, US [16] 


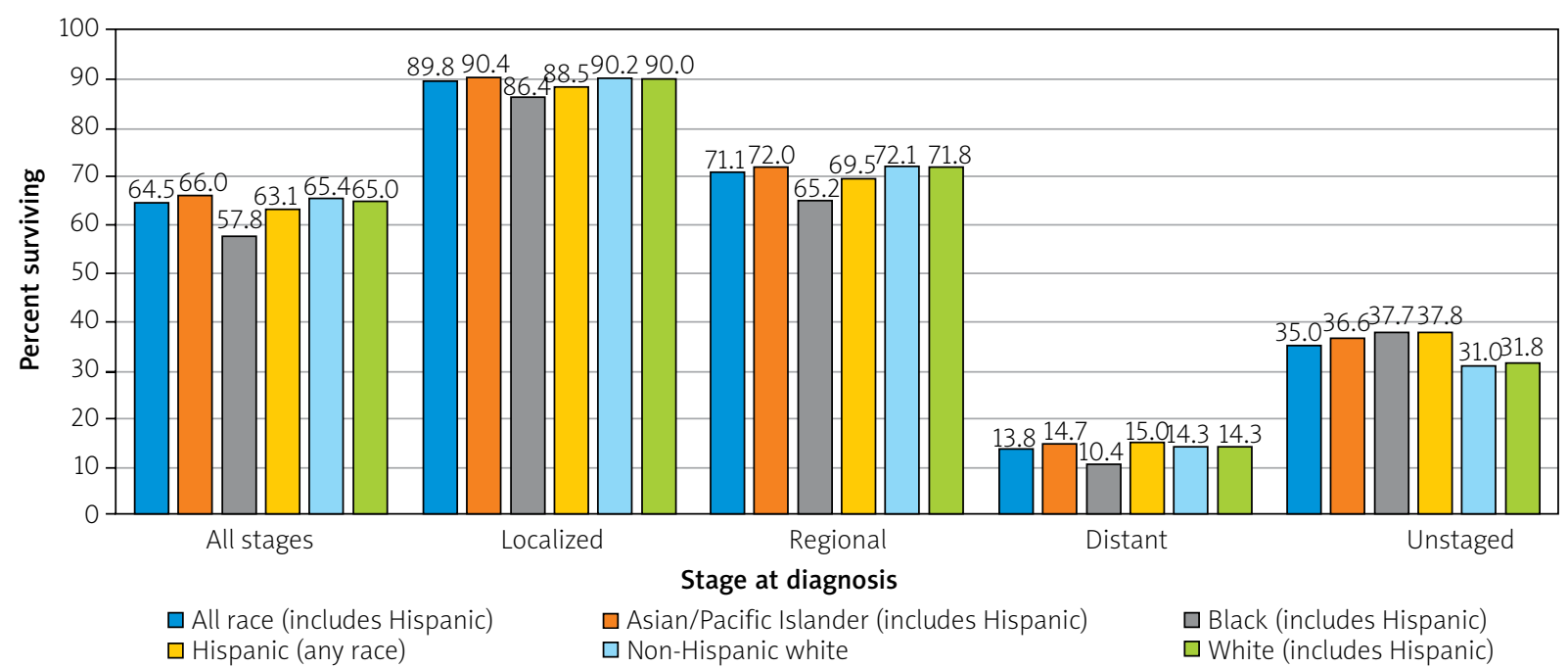

Figure 8. Colon and rectum cancer 5-year SEER relative survival rates, 2008-2014 by stage at diagnosis and race/ethnicity [16]

Meanwhile, Hispanic Americans show the same rates and survival for CRC as do white Americans. Before the mid-1980s, CRC rates had been similar in whites and blacks, but they have since diverged. As per SEER Program, the rate of CRC per 100,000 in 1975 in blacks was 56.9 and in whites was 60.2. In 2015 the rates in blacks was 44.7 and whites was 36.2 (Figure 9) [16]. Differences in racial presentation are likely have more to do with the disparity in access to quality healthcare, pre-emptive screenings, healthy foods, income, and education than a genetic component [20, 21].

\section{Sex}

Across all ages and nations, males have about a 1.5fold higher chance of developing CRC than females [9]. Among older adults in the US, the gender difference has shrunk in recent decades to mirror the gender differ-

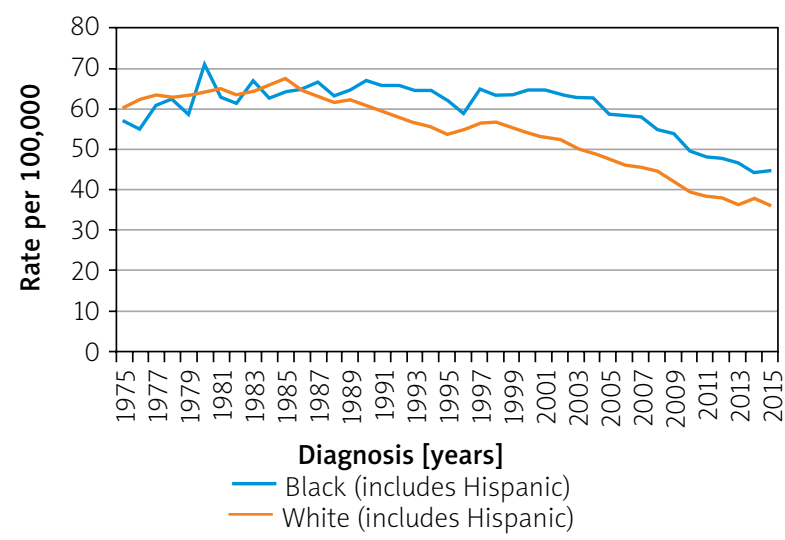

Figure 9. Colon and rectum cancer long-term trends in SEER incidence rates, 1975-2015 by race/ethnicity [16] ence among younger adults [14]. When compared to men, women are more prone to right-sided colon cancer, which is associated with a more aggressive form of neoplasia when compared to left-sided colon cancer [22]. The 5-year survival rates for females over 70 years of age was lower when compared to males [23].

\section{Age}

In the US, those over 65 years old are about three times more likely to be diagnosed with CRC than those 50-64 years old, and about 30 times more likely to be diagnosed than those 25-49 years old. While the incidence rate for the disease has decreased over the past decades among those over 50 years old, the incidence rate for those under 50 years old has actually increased [16]. Researchers believe this may be a reflection of a more sedentary lifestyle and have since recommended lowering the screening age to 45 years in order to detect cases in younger adults earlier [14].

\section{Hereditary mutations}

Hereditary CRCs account for $7-10 \%$ of all cases and include hereditary non-polyposis colorectal cancer (HNPCC), and adenomatous (FAP and MAP) and hamartomatous (PJS, JPS, PHTS) polyposis syndromes [24]. Table I lists the common hereditary syndromes, the genes involved, and the pattern of inheritance.

Up to $30 \%$ of CRC patients have a family history of the neoplasm, meaning there are probably predisposing germ-line mutations not yet identified by researchers. Those with a first-degree relative with the disease suffer a 2-4 times higher risk. The heightened risk also extends beyond first-degree relatives [24]. 
The most common hereditary syndrome is HNPCC, currently known as Lynch syndrome, which accounts for $2-4 \%$ of all cases. Like most hereditary CRC syndromes, Lynch syndrome presents a dominant pattern of heredity. Those with the disease have about a $20 \%$ chance of developing CRC by age 50 years, and about a $50 \%$ chance of developing it by age 70 years (although men still present a higher risk than women). The condition also heightens one's risk of oesophageal, endometrial, small intestine, ovarian, and stomach cancer [25]. Less than $1 \%$ of the estimated 800,000 Americans with Lynch syndrome know of their condition because the genetic diagnosis is usually made after a cancer diagnosis. Because of the cost-prohibitive nature of genetic diagnosis, family history remains the tell-tale sign of the condition $[26,27]$.

Familial adenomatous polyposis (FAP) is the second most frequent predisposing syndrome, although it accounts for less than $1 \%$ of all cases. As a polyposis condition (along with MAP), patients with FAP present with thousands of pre-cancerous colorectal polyps growing by age 10-12 years [28]. As these adenomas grow, their chance of carcinogenesis grows with them, to the point that those with FAP have an almost 100\% risk of developing CRC by age 40 years. The FAP can also occur spontaneously. Those with attenuated FAP develop fewer than 100 polyps, but a heightened risk of CRC remains. Meanwhile, MUTYH-associated polyposis (MAP) is less clinically defined, and sufferers may or may not develop an exorbitant amount of polyps [29].

Conditions of hamartomatous polyps, such as Peutz-Jeghers syndrome (PJS), juvenile polyposis syndrome (JPS), and PTEN hamartoma tumour syndrome (PHTS) are rare and poorly-understood, but they are known to follow a different progression from adenomatous polyps. These polyps follow the "landscaper effect", where the abnormal changes begin not in the epithelium (as with adenomas) but the lamina propria below, and then spread to the epithelium [30].

\section{Inflammatory bowel disease (IBD)}

Patients with chronic IBD have a two-fold risk of developing CRC. The IBD is characterised by inflammation in the colon over long periods of time. Inflammation results in the abnormal release of growth cytokines, excess blood flow, metabolic free radicals, and other factors that predispose towards carcinogenesis. The primary causes behind IBD are ulcerative colitis and Crohn's disease [31] In a recent Swedish cohort study of 9405 patients, it was found that patients with childhood onset of IBD had increased risk for any cancer, especially gastrointestinal cancers in childhood and later in life. Patients with ulcerative colitis were at higher risk of
Table I. Common hereditary syndromes associated with CRC, genes involved, and pattern of inheritance

\begin{tabular}{|c|c|c|}
\hline Condition & Gene & $\begin{array}{l}\text { Inheritance } \\
\text { pattern }\end{array}$ \\
\hline $\begin{array}{l}\text { Familial adenomatous } \\
\text { polyposis (FAP) (classic } \\
\text { and attenuated FAP) }\end{array}$ & APC & $\begin{array}{l}\text { Autosomal } \\
\text { dominant }\end{array}$ \\
\hline $\begin{array}{l}\text { Gardner's syndrome } \\
\text { (variant of FAP) }\end{array}$ & APC & $\begin{array}{l}\text { Autosomal } \\
\text { dominant }\end{array}$ \\
\hline $\begin{array}{l}\text { Turcot syndrome } \\
\text { (variant of FAP) }\end{array}$ & $\begin{array}{l}\text { APC, MLH1 or } \\
\text { PMS2 }\end{array}$ & $\begin{array}{l}\text { Autosomal } \\
\text { dominant or } \\
\text { autosomal } \\
\text { recessive }\end{array}$ \\
\hline $\begin{array}{l}\text { Hereditary non-polyposis } \\
\text { colorectal cancer (HNPCC) } \\
\text { syndrome (Lynch syndrome) }\end{array}$ & $\begin{array}{l}\text { MLH1, MSH2, } \\
\text { MSH6, EpCAM } \\
\text { and PMS2 }\end{array}$ & $\begin{array}{l}\text { Autosomal } \\
\text { dominant }\end{array}$ \\
\hline $\begin{array}{l}\text { MUTYH-associated polyposis } \\
\text { (MAP) }\end{array}$ & MUTYH, APC & $\begin{array}{l}\text { Autosomal } \\
\text { recessive }\end{array}$ \\
\hline $\begin{array}{l}\text { Juvenile polyposis syndrome } \\
\text { (JPS) }\end{array}$ & $\begin{array}{c}\text { SMAD4 } \\
(\mathrm{MADH} 4) \\
\text { BMPR1A } \\
(\mathrm{ALK} 3)\end{array}$ & $\begin{array}{l}\text { Autosomal } \\
\text { dominant }\end{array}$ \\
\hline Peutz-Jeghers syndrome (PJS) & STK11 (LKB1) & $\begin{array}{l}\text { Autosomal } \\
\text { dominant }\end{array}$ \\
\hline $\begin{array}{l}\text { Polymerase proofreading- } \\
\text { associated polyposis (PPAP) }\end{array}$ & POLE, POLD1 & $\begin{array}{l}\text { Autosomal } \\
\text { dominant }\end{array}$ \\
\hline $\begin{array}{l}\text { PTEN hamartoma tumors } \\
\text { syndrome (PHTS) }\end{array}$ & PTEN & $\begin{array}{l}\text { Autosomal } \\
\text { dominant }\end{array}$ \\
\hline Cowden syndrome & PTEN & $\begin{array}{l}\text { Autosomal } \\
\text { dominant }\end{array}$ \\
\hline $\begin{array}{l}\text { Familial colorectal cancer } \\
\text { type } X\end{array}$ & $\begin{array}{c}\text { BRCA2, KRAS, } \\
\text { APC, NTS, } \\
\text { BRAF, BMPR1A, } \\
\text { and RPS20 }\end{array}$ & $\begin{array}{l}\text { Autosomal } \\
\text { dominant }\end{array}$ \\
\hline
\end{tabular}

CRC (HR (hazards ratio) 33.3, 95\% Cl (confidence interval): 23.1 to 49.1 ) than patients with Crohn's disease $(\mathrm{HR}=5.8,95 \% \mathrm{Cl}: 3.2-10.4)$ [32].

Ulcerative colitis is characterised by inflammation and ulcers in the large intestine. Its primary cause remains unknown, although diet, stress, and exercise are known to aggravate the condition. Ulcerative colitis is believed to be an autoimmune disorder, which follows viral or bacterial infection and is known to have a hereditary component. A meta-analysis of eight studies by Jess et al. showed that ulcerative colitis increases the risk of $C R C$ by 2.4 times. Male sex, young age at the time of diagnosis with UC, and extensive colitis increase the risk of CRC [33].

Crohn's disease is also an autoimmune, and partially hereditary, inflammation of the colon, but it presents with deeper-penetrating inflammation and a lack of intestinal ulcers. Both IBDs are more common in developed countries and seem to be increasing in prevalence 
with time. The IBD has been diagnosed in an estimated 3.1 million Americans. The development seems to have an environmental or behavioural component, as those with the lowest education and income seem to be worst affected [34].

\section{Abdominal radiation}

Childhood malignancy survivors who have received abdominal radiation are at significantly increased risk of subsequent gastrointestinal neoplasms as adults, the majority being CRC. A clear radiation dose-response effect on CRC risk was noted with a $70 \%$ increase in risk for every 10-Gy increase in the radiation dose. Alkylating agent exposure had an 8.8-fold increased risk of secondary CRC [35]. Men diagnosed with prostate cancer had an increased risk of a subsequent diagnosis of CRC (All CRC: $H R=1.14 ; 95 \% ~ C l: 1.02-1.27$; Rectal Cancer: $H R=$ $1.36 ; 95 \% \mathrm{Cl}: 1.09-1.71)$. The treatment of prostate cancer with radiation was associated with an increased risk for rectal cancer $(\mathrm{HR}=2.06 ; 95 \% \mathrm{Cl}: 1.42-2.99)$ in comparison with those not treated with radiation $[36,37]$.

\section{Cystic fibrosis}

Elevated risk of CRC is seen in cystic fibrosis patients. In a recent meta-analysis of six cohort studies, which included 99,925 patients, showed that the risk of CRC was 10 times higher in patients with cystic fibrosis, with an incidence rate of 0.39 per 1000 person-years (95\% Cl: 0.072-2.08) [38].

\section{Cholecystectomy}

Cholecystectomy is associated with an increased risk of proximal and right-sided colon cancers. Intestinal exposure to bile is hypothesised as the underlying mechanism [39]. A recent meta-analysis of 10 cohort studies showed that an increased risk of CRC was found in individuals who underwent cholecystectomy $(R R=$ 1.22; 95\% Cl: 1.08-1.38) [40].

\section{Androgen deprivation therapy}

In patients with prostate cancer, who undergo androgen deprivation therapy with gonadotropin-releasing hormone $(\mathrm{GnRH})$ agonists or orchiectomy, are at increased risk of CRC. The CRC risk with use of $\mathrm{GnRH}$ agonist therapy for 25 months or more was $H R=1.31$, $95 \% \mathrm{Cl}: 1.12-1.53$, and with orchiectomy it was $\mathrm{HR}=$ $1.37,95 \% \mathrm{Cl}: 1.14-1.66$ [41].

\section{Modifiable risk factors \\ Obesity and physical inactivity}

Both obesity and physical inactivity constitute the most significant behavioural contributor to CRC devel- opment and probably explain the majority of variations among people. Studies found that those who are regularly physically active have a $25 \%$ lower chance of developing CRC. Meanwhile, those who are the most sedentary have up to a $50 \%$ increased risk of developing CRC. Physical inactivity usually results in obesity, which can alter the gut microflora and irritate and inflame large intestine epithelium, thus promoting carcinogenesis. Obesity also contributes to the development of cancer outside of the digestive tract because adipose tissue is the most inflammatory of all tissues and releases tumour-promoting cytokines into the bloodstream. Excess body weight can also disrupt metabolic processes, leading to a greater release of mutagenic free oxygen radicals.

Obese men have been found to have a $50 \%$ greater risk of colon cancer and $20 \%$ greater risk of rectal cancer (these numbers are $20 \%$ and $10 \%$ for women, respectively). The excess risk conferred by obesity is independent of the risk conferred by physical inactivity (i.e. the two risk factors are cumulative). A meta-analysis of 13 cohort studies showed that a 5 -kg weight gain was associated with a $3 \%$ increased risk of CRC [42]. Abdominal fat is especially dangerous for the development of CRC (as well as heart disease and stroke), and thus both waist circumference and BMI are used to assess increased CRC risk. Obesity and physical inactivity not only predispose towards higher rates of incidence but also decrease the likelihood of survival [43].

Increases in obesity and physical inactivity in the developed world appear to correlate with the growth of CRC incidence. The prevalence of obesity in the US has more than doubled, from $15 \%$ in 1979 to $39.8 \%$ in 2016 [44]. As many as 70\% of Americans today are overweight or obese. However, in many developed countries, this proportion has stopped growing and is even beginning to dwindle. The proportion of US adults who met physical activity guidelines increased from $41 \%$ in 2006 to $50 \%$ in 2012 [45]. Effective campaigns against obesity may be contributing to the recent successes in CRC prevention in third-category countries such as Iceland, Japan, or the US [13].

\section{Diet}

Diet can play an adverse or protective role in the development of CRC irrespective of obesity. Diet has a significant impact on the microbiome of the colon, where bacteria outnumber host cells 10-1. In fact, in a healthy body, there are more types of bacteria cells than human cells, indicating the necessity of a diverse microflora. Different foods have different effects on the microflora population and intestinal inflammation [46]. 
Red and processed meats are known to increase the risk of CRC, as well as gastric and small intestinal cancers. Prospective studies found a relative risk (RR) of 1.22 among those who consumed the most red and processed meats [47]. A meta-analysis of 60 studies recently found that consumption of red meat and processed meat increased the overall risk for CRC. CRC RR with red meat consumption was 1.12 (95\% Cl: $1.03-$ $1.21)$, and RR with processed meat consumption was 1.15 (95\% Cl: 1.07-1.24) [48]. While red meat, especially grain-fed red meat, is high in fats and inflammatory substances such as omega-6, the bulk of carcinogenesis probably comes from high-temperature cooking, curing, and smoking of meat. In 2015, the International Agency for Research on Cancer (IARC) designated processed meat as "carcinogenic" and red meat as "probably carcinogenic", mostly due to its impact on CRC risk [49].

Meanwhile, calcium, fibre, Vitamin D, and fruit and vegetables have all been shown to have a protective effect against CRC. Folate supplementation appears to inhibit carcinogenesis but promote the growth of existent tumours. This complex relationship leads most agencies to advise against folate consumption unless consumers are pregnant or have a specific metabolic disorder, such as an MTHFR mutation, which predisposes to high homocysteine levels. Fibre found commonly in fruit, vegetables, and whole grains are especially protective because they promote faster transit times for stool and thus minimise the exposure to potential carcinogens [50].

\section{Smoking}

In 2009, the IARC concluded that smoking tobacco does indeed cause CRC. Smoking is the leading preventable cause of cancer deaths, largely due to its impact on lung cancer. The relative CRC risk of regular smoking was found to be 1.18 [51]. Smoking was found to predispose more towards rectal cancer and to be more likely to cause tumours associated with common molecular abnormalities, such as high microsatellite instability, CpG methylation, and BRAF mutation. The mutagens in tobacco smoke probably promote these and other carcinogenic mutations [52]. A recent meta-analysis of 14 prospective cohort studies showed that former $(\mathrm{HR}=1.12 ; 95 \% \mathrm{Cl}: 1.04-1.20)$ and current smoking $(\mathrm{HR}=1.29,95 \% \mathrm{Cl}: 1.04-1.60)$ were associated with poorer CRC prognosis compared with never smoking and current smoking. Smoking cessation was associated with improved overall and CRC-specific survival [53].

\section{Alcohol}

Moderate to heavy alcohol consumption (greater than one daily serving) are associated with increased risk of CRC $[54,55]$. People who drink 2-3 alcoholic beverages a day have a $20 \%$ increased risk of developing CRC, while for those over three drinks, this risk increases to $40 \%$. The association is stronger in men, probably due to hormone-related variations in alcohol metabolism. Men are also more likely to drink larger quantities and under-report how much they drink [51]. A meta-analysis of 61 studies showed that the CRC RRs were 1.21 (95\% Cl: 1.13-1.28) for moderate (2-3 drinks/day) and 1.52 (95\% Cl: $1.27-1.81)$ for heavy $(\geq 4$ drinks/day) alcohol drinking [55].

\section{Medications}

Long-term use of non-steroidal anti-inflammatory drugs (NSAIDs) such as aspirin has been shown to lower the risk of CRC. Aspirin users with CRC also seem to have less aggressive tumours and greater survival. The NSAIDs lessen intestinal inflammation and thus protect against CRCs as well as gastric and small-intestinal cancers. However, the extent of the benefit has not been quantified, and NSAIDs are associated with a greater risk of gastrointestinal bleeding and heart attack, and thus are not recommended for the prevention of CRC in the general population. Nevertheless, the US Preventive Task Force does recommend low-dose aspirin for those over 50 years old with a heightened risk of cardiovascular disease or CRC [56].

Sulindac is another NSAID that has yielded conflicting results in the prevention and treatment of FAP or sporadic colorectal adenomas. To circumvent bleeding risk and cardiac toxicity, sulindac has been used in combination with the ornithine decarboxylase inhibitor difluoromethylornithine, which resulted in a $92 \%$ reduction in advanced adenomas in patients without FAP. A further combination with a statin (atorvastatin), which exhibits chemopreventive effects against CRC, yielded an $80-85 \%$ reduction in the proliferation of colon cancer in rats. The combined use of a statin and aspirin in a 5-year case-control study showed a $62 \%$ decrease in CRC risk, which was far greater than the effect of either drug alone. Moreover, the combination failed to inhibit progression in those with advanced adenomas or colon cancer. A clinical assessment of the NSAID/statin duo in combination with a chemotherapeutic agent has not yet been conducted in humans but has shown promise in animal models [57].

The protective effects of postmenopausal hormone use remain controversial. While observational studies seem to find a decreased risk of CRC, long-term, randomised trials cannot replicate the result. Likewise, oral contraceptives were once believed to decrease CRC risk, although current studies have found no evidence in support of this claim [58]. 
Studies seem to suggest that oral bisphosphonates (BPs), which are used in the prevention and treatment of osteoporosis, may reduce $C R C$ risk. Those with regular BP use had a CRC odds ratio of 0.87. Bisphosphonates can promote the immune response to cancer and inhibit tumour angiogenesis, invasion, and adhesion of tumour cells, and thus overall tumour progression. Nitrogen-containing BPs inhibit protein prenylation through the inhibition of the cholesterol synthesis pathway, which can also disrupt cancer cell growth and metastasis. Along with reduced CRC risk, BPs are also associated with reduced risk of breast cancer, all gastrointestinal cancers, and bony metastases [59].

Angiotensin-converting enzyme inhibitors (ACE-I), used in the treatment of hypertension, have also been demonstrated to reduce the risk of CRC. A large case-control study with patients with hypertension showed a 0.84 odds ratio of developing CRC for those with 1 year of ACE-I exposure, and 0.75 odds ratio for those with 5 years of exposure. The strength of association increased with dosage. However, the benefits seemed to level off after 5 years of treatment [60].

\section{Diabetes and insulin resistance}

Diabetes mellitus is known to predispose towards a vast array of cancers. Mostly, this increased risk is due to shared risk factors such as obesity and a sedentary lifestyle. Diabetics also present with abnormally high blood sugar levels, which can promote the carcinogenic shift to glycolysis (known as the Warburg effect) by accelerating glucose metabolism. However, those with type 2 diabetes have an increased risk of CRC even after adjusting for body mass index (BMI), physical activity, and other shared factors. Some studies have suggested that metformin, a drug that lowers blood glucose levels in diabetics, can also reduce CRC risk, although other trials have found no association. The incidence of diabetes and obesity continue to grow in the developed world, which has led many to speculate that they are the underlying factor behind the increase in CRC incidence. The population of Americans with diabetes more than doubled in the period from 1990 to 2012. The CDC estimates that 29 million Americans (or $9 \%$ of the population) suffer from diabetes, and as many as 8 million of them go undiagnosed [61].

A recent meta-analysis of 29 prospective cohort studies (62,924 cases) in China reported a $27 \%$ higher risk of CRC associated with diabetes [62]. In a recent Chinese prospective study of 0.5 million participants with diabetes, the adjusted HR of CRC was 1.18 (95\% Cl: 1.04-1.33). Longer duration of diabetes was associated with decreased HR [63].

\section{Prevention}

Variations and trends in CRC incidence suggest that the disease has a large behavioural component and that effective prevention is possible. Advances in CRC screenings have fuelled the reduction in mortality in the developed world, even in the face of growing incidence in many nations. There are several recommended methods for screenings, all of which have a comparable ability to improve survival if performed appropriately. Among these screenings are colonoscopies every 10 years or computed tomographic colonography (CTG), double-contrast barium enemas, or flexible sigmoidoscopies every 5 years. Annual high-sensitivity stool tests of different varieties are also comparably effective and less invasive [64].

Behavioural modification holds great promise for significantly reducing the incidence of CRC, as shown by the success of third-category countries such as Iceland, Japan, and the US. As previously mentioned, physical activity and maintaining a healthy weight can each reduce the risk of CRC by some $25 \%$, culminating in a $50 \%$ reduction [43].

Modifications to the diet can further reduce CRC risk. Calcium and vitamin D from supplements or lowfat dairy products, fibre from fruit, vegetables, and whole grains, and antioxidants such as those in fruit and coffee have yielded some reductions in CRC risk. Other potentially protective foods include garlic, magnesium, fish, and vitamin $B_{6}$. Folate supplementation has been shown to be effective in preventing the formation of tumours but may lead to the growth of already-present tumours, and is therefore not recommended for the population. Lastly, a reduction in alcohol, tobacco, and red and processed meat consumption could together lower CRC risk by over $50 \%[46,47,49]$.

Certain medications that are commonly prescribed for other conditions, such as NSAIDs, statins, and bisphosphonates have been shown to protect against CRC, especially when used in combination. These compounds may also facilitate the treatment of CRC in combination with chemotherapeutic agents [57-60]. However, due to the limited data available and possible side-effects, these medications are not recommended to the general public simply for the prevention of CRC. Those with hereditary predispositions towards CRC (the most common of which is Lynch syndrome) are more likely to benefit from genetic testing, lifestyle modification, and prophylactic medication $[25,26]$.

\section{Conclusions}

Cancers of the colon and rectum are among the most common and deadly neoplasms, and their global incidence and mortality are likely to increase in the 
coming decades. In 2018, nearly 2 million diagnoses and 1 million deaths are expected due to this neoplasm. The incidence of CRC has been exacerbated by the proliferation of poor diet and sedentary lifestyle in developed nations. However, successes in treatment and early diagnosis have enabled a reduction in mortality from the disease among all high-HDI nations, and lifestyle modification has even enabled a reduction in incidence in the highest-HDI nations. Known hereditary mutations cause $7-10 \%$ of cases (and possibly more), and greater awareness and testing for these conditions could further improve survival. Ultimately, avoidance of physical inactivity, obesity, red and processed meat, alcohol, and smoking, and a greater intake of fibre and certain supplements and medications hold the most promise in preventing CRC among the general population around the world.

\section{Conflict of interest}

The authors declare no conflict of interest.

\section{References}

1. Ewing I, Hurley JJ, Josephides E, Millar A. The molecular genetics of colorectal cancer. Frontline Gastroenterol 2014; 5: 26-30.

2. Vogelstein B, Fearon ER, Hamilton SR, et al. Genetic alterations during colorectal-tumor development. N Engl J Med 1988; 319: 525-32.

3. Peifer M. Developmental biology: colon construction. Nature 2002; 420: 274-5.

4. Kosinski C, Li VS, Chan AS, et al. Gene expression patterns of human colon tops and basal crypts and BMP antagonists as intestinal stem cell niche factors. Proc Natl Acad Sci USA 2007; 104: 15418-23.

5. Medema JP, Vermeulen L. Microenvironmental regulation of stem cells in intestinal homeostasis and cancer. Nature 2011; 474: 318-26.

6. Sideris M, Papagrigoriadis S. Molecular biomarkers and classification models in the evaluation of the prognosis of colorectal cancer. Anticancer Res 2014; 34: 2061-8.

7. Kekelidze M, D’Errico L, Pansini M, et al. Colorectal cancer: current imaging methods and future perspectives for the diagnosis, staging and therapeutic response evaluation. World J Gastroenterol 2013; 19: 8502-14.

8. Colussi D, Brandi G, Bazzoli F, Ricciardiello L. Molecular pathways involved in colorectal cancer: implications for disease behavior and prevention. Int J Mol Sci 2013; 14: 16365-85.

9. Bray F, Ferlay J, Soerjomataram I, et al. Global cancer statistics 2018: GLOBOCAN estimates of incidence and mortality worldwide for 36 cancers in 185 countries. CA Cancer J Clin 2018; 68: 394-424.

10. Ferlay J, Ervik M, Lam F, et al. Global Cancer Observatory: Cancer Today. Lyon, France: International Agency for Research on Cancer. Available from: https://gco.iarc.fr/today, Accessed 02 November 2018.

11. Ferlay J, Ervik M, Lam F, et al. (2018). Global Cancer Observatory: Cancer Today. Lyon, France: International Agency for
Research on Cancer. Available from: http://gco.iarc.fr/today/ data/factsheets/cancers/10_8_9-Colorectum-fact-sheet.pdf, accessed 02 November 2018.

12. Surveillance, Epidemiology, and End Results (SEER) Program (www.seer.cancer.gov) SEER ${ }^{\star}$ Stat Database: Incidence - SEER 18 Regs Research Data+Hurricane Katrina Impacted Louisiana Cases, Nov 2015 Sub (1973-2013 varying) - Linked To County Attributes - Total U.S., 1969-2014 Counties, National Cancer Institute, DCCPS, Surveillance Research Program, Surveillance Systems Branch, released April 2016, based on the November 2015 submission.

13. Arnold M, Sierra MS, Laversanne M, et al. Global patterns and trends in colorectal cancer incidence and mortality. Gut 2017; 66: 683-91.

14. Edwards BK, Ward E, Kohler BA, et al. Annual report to the nation on the status of cancer, 1975-2006, featuring colorectal cancer trends and impact of interventions (risk factors, screening, and treatment) to reduce future rates. Cancer 2010; 116: 544-73.

15. Yin D, Morris CR, Bates JH, German RR. Effect of misclassified underlying cause of death on survival estimates of colon and rectal cancer. J Natl Cancer Inst 2011; 103: 1130-3.

16. SEER ${ }^{\star}$ Explorer: An interactive website for SEER cancer statistics [Internet]. Surveillance Research Program, National Cancer Institute. Available from https://seer.cancer.gov/explorer/. Accessed November 012018.

17. Rawla P, Sunkara T, Muralidharan P, Pradeep Raj J. Update in global trends and aetiology of hepatocellular carcinoma. Contemp Oncol 2018; 22: 141-50.

18. Stryker SJ, Wolff BG, Culp CE, et al. Natural history of untreated colonic polyps. Gastroenterology 1987; 93: 1009-13.

19. Stewart SL, Wike JM, Kato I, et al. A population-based study of colorectal cancer histology in the United States, 1998-2001. Cancer 2006; 107: 1128-41.

20. Irby K, Anderson WF, Henson DE, Devesa SS. Emerging and widening colorectal carcinoma disparities between Blacks and Whites in the United States (1975-2002). Cancer Epidemiol Biomarkers Prev 2006; 15: 792-7.

21. Lansdorp-Vogelaar I, Kuntz KM, Knudsen AB, et al. Contribution of screening and survival differences to racial disparities in colorectal cancer rates. Cancer Epidemiol Biomarkers Prev 2012; 21: 728-36.

22. Kim SE, Paik HY, Yoon H, et al. Sex- and gender-specific disparities in colorectal cancer risk. World J Gastroenterol 2015; 21: 5167-75.

23. Park HC, Shin A, Kim BW, et al. Data on the characteristics and the survival of Korean patients with colorectal cancer from the Korea central cancer registry. Ann Coloproctol 2013; 29: 144-9.

24. De Rosa M, Pace U, Rega D, et al. Genetics, diagnosis and management of colorectal cancer (Review). Oncol Rep 2015; 34: 1087-96.

25. Bonadona V, Bonaiti B, Olschwang S, et al. Cancer risks associated with germline mutations in MLH1, MSH2, and MSH6 genes in Lynch syndrome. JAMA 2011; 305: 2304-10.

26. Hampel $\mathrm{H}$, de la Chapelle A. The search for unaffected individuals with Lynch syndrome: do the ends justify the means? Cancer Prev Res (Phila) 2011; 4: 1-5. 
27. Butterworth AS, Higgins JP, Pharoah P. Relative and absolute risk of colorectal cancer for individuals with a family history: a meta-analysis. Eur J Cancer 2006; 42: 216-27.

28. Ricciardiello L, Ahnen DJ, Lynch PM. Chemoprevention of hereditary colon cancers: time for new strategies. Nat Rev Gastroenterol Hepatol 2016; 13: 352-61.

29. American Cancer Society. Colorectal Cancer Facts \& Figures 2017-2019. Atlanta: American Cancer Society; 2017. https:// www.cancer.org/content/dam/cancer-org/research/cancer-facts-and-statistics/colorectal-cancer-facts-and-figures/ colorectal-cancer-facts-and-figures-2017-2019.pdf. Accessed Nov 012018.

30. Calva D, Howe JR. Hamartomatous polyposis syndromes. Surg Clin North Am 2008; 88: 779-817, vii.

31. Lutgens MW, van Oijen MG, van der Heijden GJ, et al. Declining risk of colorectal cancer in inflammatory bowel disease: an updated meta-analysis of population-based cohort studies. Inflamm Bowel Dis 2013; 19: 789-99.

32. Olen O, Askling J, Sachs MC, et al. Childhood onset inflamma tory bowel disease and risk of cancer: a Swedish nationwide cohort study 1964-2014. BMJ 2017; 358: j3951.

33. Jess T, Rungoe C, Peyrin-Biroulet L. Risk of colorectal cance in patients with ulcerative colitis: a meta-analysis of population-based cohort studies. Clin Gastroenterol Hepatol 2012 10: 639-45.

34. Castano-Milla C, Chaparro M, Gisbert JP. Systematic review with meta-analysis: the declining risk of colorectal cancer in ulcerative colitis. Aliment Pharmacol Ther 2014; 39: 645-59.

35. Nottage K, McFarlane J, Krasin MJ, et al. Secondary colorectal carcinoma after childhood cancer. J Clin Oncol 2012; 30 2552-8.

36. Desautels D, Czaykowski P, Nugent Z, et al. Risk of colorectal cancer after the diagnosis of prostate cancer: a population-based study. Cancer 2016; 122: 1254-60.

37. Rawla P, Vellipuram AR, Bandaru SS, Pradeep Raj J. Colon carcinoma presenting as Streptococcus anginosus bacteremia and liver abscess. Gastroenterology Res 2017; 10: 376-9.

38. Yamada A, Komaki Y, Komaki F, et al. Risk of gastrointestinal cancers in patients with cystic fibrosis: a systematic review and meta-analysis. Lancet Oncol 2018; 19: 758-67.

39. Lagergren J, Ye W, Ekbom A. Intestinal cancer after cholecystectomy: is bile involved in carcinogenesis? Gastroenterology 2001; 121: 542-7.

40. Zhang Y, Liu H, Li L, et al. Cholecystectomy can increase the risk of colorectal cancer: a meta-analysis of 10 cohort studies. PLoS One 2017; 12: e0181852.

41. Gillessen S, Templeton A, Marra G, et al. Risk of colorectal cancer in men on long-term androgen deprivation therapy for prostate cancer. J Natl Cancer Inst 2010; 102: 1760-70.

42. Karahalios A, Simpson JA, Baglietto L, et al. Change in weight and waist circumference and risk of colorectal cancer: results from the Melbourne Collaborative Cohort Study. BMC Cancer 2016; 16: 157

43. Robsahm TE, Aagnes B, Hjartaker A, et al. Body mass index, physical activity, and colorectal cancer by anatomical subsites: a systematic review and meta-analysis of cohort studies. Eur J Cancer Prev 2013; 22: 492-505.
44. Hales CM, Carroll MD, Fryar CD, Ogden CL. Prevalence of obesity among adults and youth: United States, 2015-2016. NCHS Data Brief 2017; 1-8.

45. Ward BW, Clarke TC, Nugent CN, Schiller JS. Early release of selected estimates based on data from the 2015 National Health Interview Survey (National Center for Health Statistics). https://www.cdc.gov/nchs/data/nhis/earlyrelease/earlyrelease201605.pdf. Published 2016. Accessed Nov 01, 2018.

46. O'Keefe SJ. Diet, microorganisms and their metabolites, and coIon cancer. Nat Rev Gastroenterol Hepatol 2016; 13: 691-706.

47. Chan DS, Lau R, Aune D, et al. Red and processed meat and colorectal cancer incidence: meta-analysis of prospective studies. PLoS One 2011; 6: e20456.

48. Zhao Z, Feng Q, Yin Z, et al. Red and processed meat consumption and colorectal cancer risk: a systematic review and meta-analysis. Oncotarget 2017; 8: 83306-14.

49. Kim E, Coelho D, Blachier F. Review of the association between meat consumption and risk of colorectal cancer. Nutr Res 2013; 33: 983-94.

50. Song M, Garrett WS, Chan AT. Nutrients, foods, and colorectal cancer prevention. Gastroenterology 2015; 148: 1244$60 \mathrm{e} 1216$.

51. Botteri E, lodice S, Bagnardi V, et al. Smoking and colorectal cancer: a meta-analysis. JAMA 2008; 300: 2765-78.

52. Limsui D, Vierkant RA, Tillmans LS, et al. Cigarette smoking and colorectal cancer risk by molecularly defined subtypes. J Natl Cancer Inst 2010; 102: 1012-22.

53. Ordonez-Mena JM, Walter V, Schottker B, et al. Impact of prediagnostic smoking and smoking cessation on colorectal cancer prognosis: a meta-analysis of individual patient data from cohorts within the CHANCES consortium. Ann Oncol 2018; 29: 472-83.

54. Bagnardi V, Rota M, Botteri E, et al. Alcohol consumption and site-specific cancer risk: a comprehensive dose-response meta-analysis. Br J Cancer 2015; 112: 580-93.

55. Fedirko V, Tramacere I, Bagnardi V, et al. Alcohol drinking and colorectal cancer risk: an overall and dose-response metaanalysis of published studies. Ann Oncol 2011; 22: 1958-72.

56. Rothwell PM, Wilson M, Elwin CE, et al. Long-term effect of aspirin on colorectal cancer incidence and mortality: 20-year follow-up of five randomised trials. Lancet 2010; 376: 1741-50.

57. Chang WL, Jackson C, Riel S, et al. Differential preventive activity of sulindac and atorvastatin in Apc(+/Min-FCCC)mice with or without colorectal adenomas. Gut 2018; 67: 1290-8.

58. Hildebrand JS, Jacobs EJ, Campbell PT, et al. Colorectal cancer incidence and postmenopausal hormone use by type, recency, and duration in cancer prevention study II. Cancer Epidemiol Biomarkers Prev 2009; 18: 2835-41.

59. Thosani N, Thosani SN, Kumar S, et al. Reduced risk of colorectal cancer with use of oral bisphosphonates: a systematic review and meta-analysis. J Clin Oncol 2013; 31: 623-30.

60. Makar GA, Holmes JH, Yang YX. Angiotensin-converting enzyme inhibitor therapy and colorectal cancer risk. J Natl Cancer Inst 2014; 106: djt374.

61. Tsilidis KK, Kasimis JC, Lopez DS, et al. Type 2 diabetes and cancer: umbrella review of meta-analyses of observational studies. BMJ 2015; 350: g7607. 
62. Jiang Y, Ben Q, Shen $\mathrm{H}$, et al. Diabetes mellitus and incidence and mortality of colorectal cancer: a systematic review and meta-analysis of cohort studies. Eur J Epidemiol 2011; 26: 863-76.

63. Pang Y, Kartsonaki C, Guo Y, et al. Diabetes, plasma glucose and incidence of colorectal cancer in Chinese adults: a prospective study of 0.5 million people. J Epidemiol Commun Health 2018; 72: 919-25.

64. Knudsen AB, Zauber AG, Rutter CM, et al. Estimation of benefits, burden, and harms of colorectal cancer screening strategies: modeling study for the US preventive services task force. JAMA 2016; 315: 2595-609.

Received: 6.11 .2018

Accepted: 20.11 .2018 